\title{
The Homeless with Jail Experiences: An Exploratory Study
}

\section{Charisse Coston $\mathrm{TM}^{*}$ and Paul Friday C}

\author{
The Department of Criminal Justice and Criminology, The University of North Carolina at Charlotte, North \\ Carolina, USA
}

"Corresponding author: Charisse Coston TM, The Department of Criminal Justice and Criminology, The University of North Carolina at Charlotte, North Carolina, USA, E-mail address: ccoston@uncc.edu

Citation: Charisse Coston TM, Paul Friday C (2017) The Homeless with Jail Experiences: An Exploratory Study. J Forensic Sci Criminol 5(3): 302

Received Date: January 31, 2017 Accepted Date: June 29, 2017 Published Date: July 01, 2017

\begin{abstract}
Twenty homeless people were interviewed about the nature and frequency of their victimization experiences and fear of crime along with their past and current criminal justice involvement. Although this is an exploratory project we have preliminary results which form the basis for more rigorous evaluative studies in the future.
\end{abstract}

Keywords: Homeless; Jail; Prison; Crime justice

\section{Introduction}

Currently, several cities in the United States have laws against individuals doing domesticated things like eating and sleeping in public places. As a result of this, a rising number of inmates in jails and prisons are homeless at the time of their arrest, or have been homeless for a period of time, preceding their arrest. While explicitly "being homeless" isn't a crime, circumstances and situations that result from being homeless, like having to sleep on a park bench because of full shelters, certainly wind people to end up in jails and prisons. Policy is being shaped around these "undesirables" as to limit how present they are in citizen's everyday lives.

According to the U.S Department of Housing and Urban Development's Estimates of Homelessness report in 2015, on a given night, over 500,000 people (individuals and families) were homeless in the United States [1]. Sixty-nine percent of those homeless on a given night are in some type of residential housing for the homeless. That indicates that there are $31 \%$ of homeless people that reside elsewhere. California, New York, Florida, Texas and Massachusetts contain over half of the homeless population. These highly populated states also have some of the strictest laws against homeless in public spaces. There is clear evidence that the homeless population is deeply at risk but despite what the research states of the homeless, the state governments prefer to lock up these at risk individuals. Instead of providing help, the governments are increasing the risk and harming citizens more.

Kushel., et al. (2005) looked at a sample of the homeless and marginally housed adult population in California to understand the relationship between homelessness and imprisonment [2]. Looking at 1426 adults in 5 shelters, 6 midday free-meal programs, and 28 low-income residential hotels they found a vast mix of results. One of the more common findings, as will later on appear, is that there are significantly higher rates of mental illness and substance use among the homeless. Of the respondents surveyed, a quarter of them had been incarcerated in prison. Almost $4 \%$ reported being released within the past year and $4.4 \%$ reported being out on parole. Of those that had a history with imprisonment, over $90 \%$ reported to have used drugs throughout their lifetime. The study also found that the homeless that had been imprisoned were more likely to have had multiple sex partners (more than 100) and have a history of psychiatric hospitalizations.

Greenberg and Rosenheck (2008) looked at the US adult state and federal prison inmate population and its relationship with homelessness and mental illness [3]. The study found that of those in the US ASFPI population, 9.2\% had been homeless. Of that $9.2 \%, 7.5 \%$ reported being homeless in the last year, and $1.7 \%$ were homeless when they were arrested. Inmates that fit into those two homeless groups were far more likely to be arrested for a property type crime and they were more likely to have been previously involved in the criminal justice system. This study also, like the previous, reported higher rates of substance abuse and mental disorders, with $40 \%$ reporting to have used mental health services or taken medication to treat an illness prior to arrest. Demographically, homeless inmates were less likely to be married, and were less likely to have had a monthly income greater than $\$ 1,000$ a month. Greenberg and Rosenheck conducted a previous study in 2008 in regards to jail populations where they also found a higher rate of homelessness amongst those inmates as well [4]. Compared to this study, that study found there were higher rates of homeless among the jail population that the prison population (assumed to be due to the lower seriousness of crimes committed). 
Regardless, the homeless are disproportionately represented in jail and prison populations due to their unpopularity amongst domiciled citizens.

As stated before, Greenberg and Rosenheck in their "Jail Incarceration, Homelessness, and Mental Health: A National Study" (2008), found that there was a larger proportion of inmates amongst the jail population compared to the prison population that were homeless [3,4]. The study used the 2002 Survey of Inmates in Local Jails done by the Bureau of the Census for the Bureau of Justice Statistics of the U.S Department of Justice. They found, much like their later 2008 study on prison inmates, that homeless inmates on the jail population were more likely to be incarcerated for a property crime and also to have past criminal justice system involvement in nonviolent and violent offense. They were found to be more likely to have mental health and substance abuse problems and a lack of socio-demographic assets. These homeless inmates were more likely to also be unemployed, unmarried, and have less education.

Fitzpatrick and Myrstol (2008) looked to compare what Irwin (1985) titled the "rabble", those deemed unfit for the community, jail arrestees to the other arrestees in local jails in terms of their "dangerousness" [5]. The data was gathered from 47,592 interviews in 30 U.S. cities from the Arrestee Drug Abuse Monitoring Program. Within their results, they found that those arrestees of indigenous descent were more likely to be homeless, and blacks were far less likely than whites to be homeless; this contradicts the African American disproportionate representation in jail/prison populations. Again, there were findings that the homeless were more likely to use drugs and have experience with substance abuse treatment programs. Another finding in the study is that arrestees in urban areas had a significantly higher probability of being homeless. This is evident in the 2014 statistics previously stated, indicating the higher populated states having higher levels of homelessness.

Fitpatrick and Myrstol (2008) also found that homeless arrestees were significantly less likely to be held in jail for a felony offense and violent offense. They found that homeless arrestees were in fact less dangerous in relation to the arrestee population. The analysis in this study agreed with Irwin's (1985) assessment that the function of jails was to hold those deemed unfit and unwanted by the community, despite their true dangerousness levels. This study is consistent in the previous findings that the homeless are victimized by the law simply because of their status as homeless and not as a true societal threat.

Looking specifically at New York City, Metraux and Culhane (2006) looked at the histories of individuals staying in public shelters in the city (NYC having the largest shelter system in the US) [6]. The study found that of those that lived/stayed in homeless shelters in NYC, $23.1 \%$ had been incarcerated within the previous two years. The study found that those who were released from the jails and prisons used shelters as a transitional period after release. This study, however, did contain data from a 1997 sample.

McNiel., et al. (2005) studied those in the San Francisco County Jail system and evaluated the rates of homelessness and mental illness of those incarcerates [7]. They found that of their sample of 12,934 individuals booked into jail within the first 6 months of $2000,16 \%$ of them were homeless. $18 \%$ of those who were incarcerated were identified as having a mental disorder. They found that the homeless had elevated rates of mental disorder, and they have a higher rate of co-occurring substance related disorders than those who were not homeless. This study also found that inmates who were homeless and had co-occurring severe mental disorders and substance-related disorders were held in jails longer than inmates charged with similar crimes. This data coincides with the statistics showing California as a whole, having the largest homeless population. The study also determined that homelessness is not associated with elevated rates of violence, though that is what their criminal records infer.

According to all of these research studies, despite what is portrayed through the media, the homeless population is the least threatening to society in terms of criminality. More often than not, they are arrested based on property crimes, which coincide with the laws that prohibit them from "loitering" and "living" (sleeping, eating, and bathing) in certain areas. These homeless individuals are not representative of the disproportionate number of African American's that are homeless, and the African American's in prison. These studies indicate that the homeless are far more likely to be white or of another heritage. Another factor is that many of these homeless individuals suffer from some type of substance abuse or mental disease. Instead of being treated for their disease, these individuals are kept in jails and prisons for extended periods of time, in order to please the public. Public Policy has not changed to help these individuals through their problems and help them out of homelessness, but instead policy currently aims to target and lock up homeless individuals. Interestingly, jails and prisons today are overpopulated and a decent percentage of these populations are made up of the homeless, who are in fact less violent and suffer from various disadvantages.

\section{Methodology}

The research study was conducted at the Arrest Processing Center at Jail North. The first sample was selected from a list of arrestees who entered the jail from 10:00 PM and before 4:00 the next day. From this, a master list was constructed of all people who were arrested. Those selected for interviews were either listed as being homeless or resided at one of the nine homeless addresses. If someone's address was listed as "unknown," they were asked about their residence to determine if they were homeless. The second sample derived from the arrest processing sheets made at the time of booking at 4:00 PM, when incarcerated, and through 10:00 PM until they left. The same criteria were used for the first sample to be selected for interviews (Friday \& Coston, 2012). 
When interviewers approached those who met the possible criteria, they were identified as independent researchers and not Sheriff Office employees. During this process, they were informed that it was solely voluntary and of the purpose of the study, which was to determine the needs and experiences of arrestees (Friday \& Coston, 2012). Furthermore, they were told that information received would remain confidential. They also would not be identified, and when the interview was completed, a candy bar would be given as an incentive.

The national Arrestee Drug Monitoring Program also used this methodology, but there was one variance. Since this search was done at Jail North and not in Charlotte, some arrestees that were transported to Jail Central were not able to be approached for interviews. Interviews in Charlotte were able to locate arrestees assigned to housing and interview them in the pods (Friday \& Coston, 2012).

\section{Results}

The average age for selection is 39, 75.6\% are African American and 20\% are Caucasian.

\begin{tabular}{|c|c|c|}
\hline Race & $\boldsymbol{f}$ & $\%$ \\
\hline White & 4 & 20.0 \\
\hline Black/African Amer & 15 & 75.0 \\
\hline Hispanic/Latino & 1 & 5.0 \\
\hline Total & 20 & 100.0 \\
\hline
\end{tabular}

Table 1: Race of homeless

\begin{tabular}{|c|c|c|}
\hline Gender & $\boldsymbol{f}$ & $\boldsymbol{\%}$ \\
\hline Male & 17 & 85.0 \\
\hline Female & 3 & 15.0 \\
\hline Total & 20 & 100.0 \\
\hline
\end{tabular}

Table2: Gender of homeless

In terms of length of residence, $60 \%$ of the homeless have lived in Charlotte for more than 5 years, and $30 \%$ have lived in Charlotte for their entire life.

\begin{tabular}{|c|c|c|}
\hline Marital Status & $\boldsymbol{f}$ & $\boldsymbol{\%}$ \\
\hline Single & 12 & 60.0 \\
\hline Married & 1 & 5.0 \\
\hline With Someone & 3 & 15.0 \\
\hline Divorced & 4 & 20.0 \\
\hline Total & 20 & 100.0 \\
\hline
\end{tabular}

Table 3: Marital status

$60 \%$ of the homeless never have been married, and $20 \%$ are divorced.

\begin{tabular}{|c|c|c|}
\hline Grade & $\boldsymbol{f}$ & $\%$ \\
\hline 8 & 2 & 10.0 \\
\hline 9 & 1 & 5.0 \\
\hline 10 & 2 & 10.0 \\
\hline 11 & 2 & 10.0 \\
\hline 12 & 13 & 65.0 \\
\hline Total & 20 & 100.0 \\
\hline
\end{tabular}

Table 4: Education level of the homeless

$65 \%$ of the homeless had a high school diploma or GED equivalent.

\begin{tabular}{|c|c|c|}
\hline & $\boldsymbol{f}$ & $\%$ \\
\hline Felony & 6 & 30.0 \\
\hline Misdemeanor & 11 & 55.0 \\
\hline Traffic & 1 & 5.0 \\
\hline Ordinance & 2 & 10.0 \\
\hline Total & 20 & 100.0 \\
\hline
\end{tabular}

Table 5: Felonies-Misdemeanors - first charge 
In terms of offenses, no arrestee had more than three known charges. The charge most serious charge found was disturbing the peace. $35 \%$ of their first charges were property offenses, and only $25 \%$ were violent.

\begin{tabular}{|c|c|c|}
\hline & $\boldsymbol{f}$ & $\boldsymbol{\%}$ \\
\hline Misdemeanor & 4 & 20.0 \\
\hline Ordinance & 1 & 5.0 \\
\hline Total & 5 & 25.0 \\
\hline System & 15 & 75.0 \\
\hline Total & 20 & 100.0 \\
\hline
\end{tabular}

Table 6: Felony-Misdemeanor second charge

\begin{tabular}{|c|c|c|}
\hline & $\boldsymbol{f}$ & $\boldsymbol{\%}$ \\
\hline Misdemeanor & 1 & 5.0 \\
\hline System & 19 & 95.0 \\
\hline Total & 20 & 100.0 \\
\hline
\end{tabular}

Table 7: Felony-Misdemeanor third charge

In terms of housing, $45 \%$ were identified as homeless at the time of arrest living in a shelter, and $35 \%$ were living with family/ friends. More information shows that 25\% have been homeless for less than a year, $12 \%$ for less than 2 years, $31.3 \%$ less than 3 years, and $18.9 \%$ less than three years (Friday \& Coston, 2012).

\begin{tabular}{|c|c|c|}
\hline Arrest housing & $\boldsymbol{f}$ & $\boldsymbol{\%}$ \\
\hline Shelter & 9 & 45.0 \\
\hline Public place - streets & 1 & 5.0 \\
\hline Friends/family & 7 & 35.0 \\
\hline Woods & 2 & 10.0 \\
\hline Jail/Prison & 1 & 5.0 \\
\hline Total & 20 & 100.0 \\
\hline
\end{tabular}

Table 8: Housing listed at time of arrest by Sheriff's Office

When evaluating how the homeless manage, $70 \%$ take advantage of city and private food programs.

\begin{tabular}{|c|c|c|}
\hline Source & $\boldsymbol{f}$ & $\boldsymbol{\%}^{*}$ \\
\hline $\begin{array}{c}\text { City / private food } \\
\text { programs }\end{array}$ & 14 & $70 \%$ \\
\hline Friends/family & 4 & $20 \%$ \\
\hline Buy own & 4 & $20 \%$ \\
\hline Panhandle & 4 & $20 \%$ \\
\hline Food Stamps & 3 & $15 \%$ \\
\hline Go through garbage & 1 & $10 \%$ \\
\hline
\end{tabular}

Table 9: Source of food

* Will not equal $100 \%$ since there were multiple selections

There were also six people who listed multiple places where they would sleep. $65 \%$ reported sleeping in shelters, $45 \%$ with friends/ family, $20 \%$ near doorways or abandoned buildings, $20 \%$ said on the street, and $11.1 \%$ said in the woods. For sources of medical care, $70 \%$ reported using the emergency room when they were sick and needed medical attention. 30\% reported being on some type of medication, and 33.3\% reported having health problems (Friday \& Coston, 2012).

\begin{tabular}{|c|c|c|}
\hline Source & N & \%* $^{*}$ \\
\hline ER & 14 & $70 \%$ \\
\hline Self-treatment & 3 & $15 \%$ \\
\hline Social Security & 1 & $5 \%$ \\
\hline Family member & 1 & $5 \%$ \\
\hline Never ill & 1 & $5 \%$ \\
\hline
\end{tabular}

Table 10: Source of health care

When comparing "unknown" and "homeless" use of services, those with unknown addresses who are technically homeless are less likely to use homeless services than those with a homeless destination (Friday \& Coston, 2012). 


\begin{tabular}{|c|c|c|}
\hline Service & Unknown Address & Homeless Address \\
\hline Living in shelter before arrest & $20 \%$ & $60 \%$ \\
\hline Living in shelter at time of arrest & $30 \%$ & $60 \%$ \\
\hline Uses city/private food sources & $60 \%$ & $80 \%$ \\
\hline Uses shelters to sleep & $50 \%$ & $80 \%$ \\
\hline Uses shelters for showers & $30 \%$ & $80 \%$ \\
\hline Admits drug problem & $50 \%$ & $70 \%$ \\
\hline
\end{tabular}

Table 11: Comparison of "homeless and "unknown" address arrestee utilization of services

When looking at victimization, $40 \%$ reported being victimized since their homeless status, and $30 \%$ reported being victimized within the last year. $40 \%$ are more fearful of violent victimization while $35 \%$ reported fearing being a victim of property crime. The participants said they frequently avoid places where drugs are sold, unfamiliar places, where prostitutes hang out, etc. $40 \%$ also said they carry something for their own protection. Five said they carry a knife, and one reported carrying a gun (Friday \& Coston, 2012).

\begin{tabular}{|c|c|}
\hline \multicolumn{2}{|c|}{ Victimization } \\
\hline Assaults & 2 \\
\hline Robbery & 4 \\
\hline Fear of Violent Victimization & $40 \%$ \\
\hline Fear of Property Victimization & $35 \%$ \\
\hline Total Victimized Since Homeless & $8(40 \%)$ \\
\hline Total Victimized in the Last Year & $6(30 \%)$ \\
\hline
\end{tabular}

Table 12: Victimization and Fear

\begin{tabular}{|c|c|}
\hline Places avoided & $\boldsymbol{f}$ \\
\hline Where drugs are sold & 5 \\
\hline Unfamiliar places & 4 \\
\hline Where prostitutes hang out & 3 \\
\hline Over-crowded places & 3 \\
\hline Abandoned buildings & 2 \\
\hline Deserted places & 2 \\
\hline Parks & 2 \\
\hline
\end{tabular}

Table 13: The places homeless avoid

When addressing the needs of the homeless who were interviewed, the most frequent responses were employment and a place to live. When asked what their major problems were, half said it was alcohol and other common answers were unemployment, their criminal record, their mental health, and lack of family support (Friday \& Coston, 2012).

\begin{tabular}{|c|c|c|c|}
\hline \multicolumn{2}{|r|}{ Need } & $f$ & $\%$ \\
\hline & Family & 3 & 15.0 \\
\hline & Food & 2 & 10.0 \\
\hline & Job & 4 & 20.0 \\
\hline & Stay out of trouble & 1 & 5.0 \\
\hline & Clothes & 1 & 5.0 \\
\hline & Shelter & 4 & 20.0 \\
\hline & Education & 1 & 5.0 \\
\hline & Money & 3 & 15.0 \\
\hline & Total & 19 & 95.0 \\
\hline Missing & System & 1 & 5.0 \\
\hline & Total & 20 & 100.0 \\
\hline
\end{tabular}

Table 14: What the homeless say they need 


\section{Summary, Concluding Remarks and Suggestions for addressing the problems of the home- less}

Our data highlight the following profile:

1. The homeless are disproportionately single (never married) African American males

2. They are long-term Charlotte residents, not those coming to Charlotte from elsewhere in order to receive Charlotte services

3. Two-thirds have high school diplomas or GED degrees

4. Within this sample, none had been in the military

$5.88 \%$ of the charges are for misdemeanor property or public nuisance offenses

6. $75 \%$ have been homeless for more than one year

7. $70 \%$ rely on city/private food programs

8. $65 \%$ rely on shelters for their places to sleep and half use the shelters for showers

9. $70 \%$ rely on emergency room services for medical attention

10. $40 \%$ have been victims of a crime since being homeless

11. 10 of the 20 indicate that they have either an alcohol or drug problem; there are no data on mental health issues

12. Those entering the jail with an "unknown" address that is actually homeless are less likely to avail themselves of services than those designated as "homeless."

\section{The role of criminal justice and other community agencies}

We estimate that in a given week $5 \%$ of those entering the jail are homeless. They are charged with relatively minor charges yet they occupy the time and resources of both the city police and the Sheriff's Office. The criminal justice system is not in a position to adequately provide any services to the homeless. They are figuratively in a revolving door. Half of those interviewed admit to having an alcohol or substance abuse problem but it is not known if the problem was a precursor or result of being homeless.

There is little the criminal justice system can do except to find ways to aid the homeless by protecting them from victimization, notifying them of available services and helping them to maintain a safe environment.

This research focused on the homeless themselves and not on the services available in Charlotte for them. There are some questions being asked nationally and we offer them as a checklist for those working with and for the homeless in Charlotte:

Premise: The homeless in Charlotte deserve secure lodging, decent food, appropriate medical aid and facilities for maintaining personal hygiene. The mentally disabled among them deserve support, care, treatment and rehabilitation. One approach to this problem might call for an expansion of the present mental health and social service support.

1. To what extent do mental health professionals and the social service personnel look to the voluntary sector to respond to the needs of the homeless?

2. Are mental health professionals passing on its burdens to social service personnel and criminal justice agencies?

3. To what extent, collectively and individually, are the state, city and county responsible for resolving the problems of homelessness? Have the government agencies resolved the issues of funding and responsibility relative to the cost of shelters, food, and medical care?

4. Are mental health professionals certain before releasing patients that they are fit to be released? Are they certain that every patient who is released has a secure residence? Is the process of reintegration into society gradual or abrupt? Does the mental health profession sure it has adequately qualified professionals available for service in facilities which cater to the homeless?

5. Do social service agencies provide special assistance to the homeless? This special assistance involves helping them to apply for benefits, gather lost or stolen documents, helping them to complete necessary forms and unravel problems that may arise.

6. Are there provisions for social service personnel to work at the shelters? Social service personnel can help in these shelters to establish placement elsewhere. The state of homelessness, if at all, should be temporary, not too attractive. The goal should be to help resolve their situation.

7. To what extent has the community leadership mobilized individual citizens to donate items, e.g., clothes etc that they no longer use to charities that assist the homeless? To what extent has the same leadership educated the general public sufficiently to understand the state of homelessness and to become conscious of its problem?

Perspective: There is a thin line between assisting the homeless and pacifying their state of existence, which perpetuates homelessness. Public assistance can assist the homeless, but the promise of overall relief for the plight of homeless has to come from within each homeless individual. Some of the homeless must cope with their problems alone before returning to a normal lifestyle; for others, living on the streets is a permanent way of life and therefore no social agency's help will do much to rectify their situation. Shelters can be set up and more charities can be offered, but these acts only palliate the pain of homelessness; they do not remedy it. 


\section{Implications and Suggestions}

This study is merely a "snapshot" of the homeless who are arrested and processed at the jail during a random Spring/Summer week. The data suggest the following:

1. The actual number of homeless who are processed is about $5 \%$ and is a manageable number for early intervention.

2. About $60 \%$ of those with "unknown" addresses are actually homeless and they appear not to avail themselves of local services. This suggests that a few screening questions could be used by pre-trial release to identify this group and provide appropriate information.

3. This suggests that if each is "flagged" the next time they are arrested they could be offered the opportunity to utilize jail-based services - especially substance abuse since half of them admit to having an alcohol or drug problem.

4. The percentage of homeless in the "homeless" and "unknown" address lists can be used to estimate the percentage of homeless $( \pm 7 \%)$ actually in the jail at any given point in time.

\section{Acknowledgement}

This project was funded by Mecklenburg County, Charlotte NC (USA).

\section{References}

1. The US Department of Housing and Urban Development (2015) Point-in-Time Estimates of Homelessness. AHAR to Congress.

2. Fitzpatrick K, Myrstol B (2008) The Jailing of America’s Homeless: Evaluating the Rabble Management Thesis. Crime \& Delinquency 57: 271-97.

3. Greenberg G, Rosenheck R (2008) Jail Incarceration, Homelessness and Mental Health: A National Study. Psychiatr Serv 59: 170-7.

4. Greenberg G, Rosenheck R (2008) Homelessness in the State and Federal Prison Population. Crim Behav Ment Health 18: 88-103.

5. Kushel M, Hahn J, Evans J, Bangsberg D, Moss A (2005) Revolving Doors: Imprisonment Among the Homeless and Marginally Housed Population. Am J Public Health 95: 1747-52.

6. McNiel D, Binder R, Robinson J (2005) Incarceration Associated With Homelessness, Mental Disorder, And Co-occurring Substance Abuse. Psychiatr Serv 56: $840-6$.

7. Metraux S (2006) Recent Incarceration History among a Sheltered Homeless Population. Crime \& Delinquency 52: 504-17.

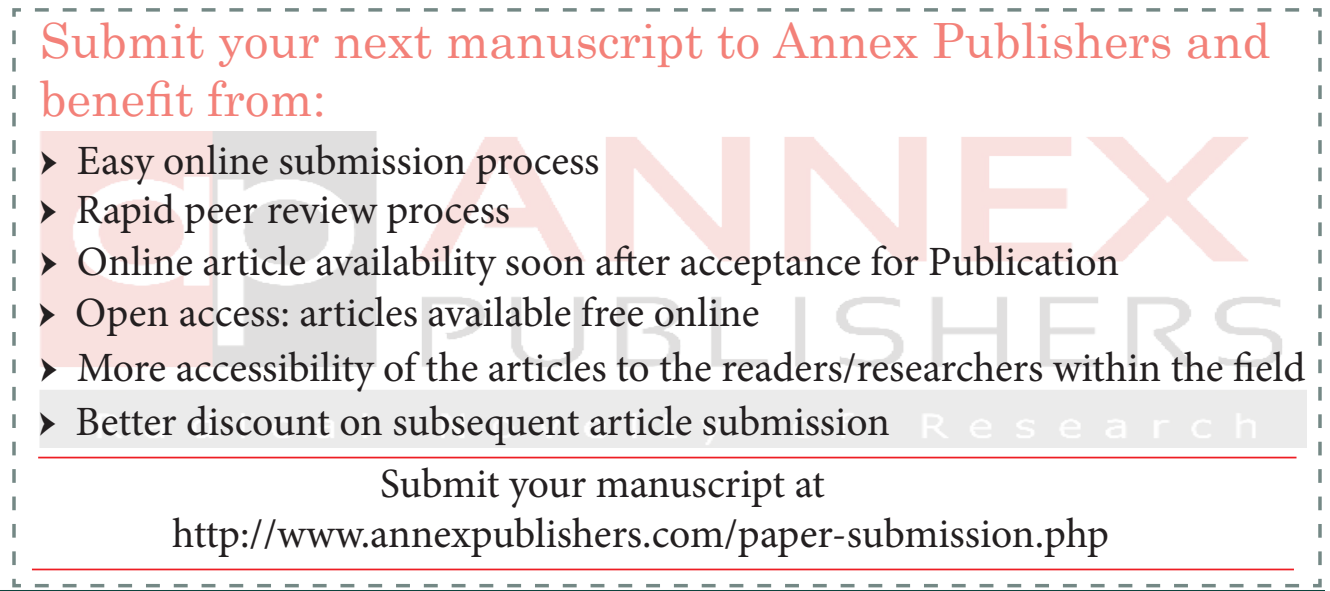

